\title{
Come to the Beautiful Flower Garden
}

\author{
Kyung-chul Kim ${ }^{1}$ and Ko eun Lee ${ }^{2 *}$ \\ ${ }^{1}$ Professor, Department of Early Childhood Education, \\ Korea National University of Education \\ ${ }^{2}$ Doctor's course, Department of Early Childhood Education, \\ Korea National University of Education \\ ${ }^{1}$ kbrian@knue.ac.kr, ${ }^{2}$ sarang2162@naver.com
}

\begin{abstract}
The purpose of this study was to investigate the process of young child's feeling of beauty, natural wonder and aesthetics by living their everyday lives and analyzing the process of change of young children in flower garden project. The subjects of this study were 5 years old kindergarten students at G city. The study period was 4 weeks in May, 2015. As a result of the research, the young children specifically thought about the flower which they thought vaguely beautiful, especially the beauty. They also decorated the flower garden with information about the flower they explored and invited their younger brother to the flower garden to open the flower garden. Through this process, young children have not only the beauty of nature and the preciousness of life, but also the experience of helping and sharing with others. Also, through the project approach, infants could explore the understanding of ecosystems through flowers and exploring ways to protect them.
\end{abstract}

Keywords: Project approach, teaching-learning, flower

\section{Introduction}

Humans constantly pursue beauty in life. This human nature appears indiscriminately in children or adults. In particular, the beauty of nature puts humans in awe, and they cannot help but marvel at the beauty within nature. Various activities to experience beauty and aesthetic sense in natural objects are important contents for early childhood education. Moreover, an interest in the beauty of nature naturally becomes the foundation for the behavioral practice of protecting and preserving the environment.

As suggested by Lim, Ji Sook [1], there is a need for a study garden in current education where children can constantly experience nature close by. Thus, it is highly significant to provide young children with the environment and media to be close to nature. Flowers are one of the natural objects that can be commonly found in the surrounding environment. In particular, young children become highly interested in various colors and shapes of flowers from the small ones they can easily find around them in spring. There are activities about plants and flowers of each season in the daily life theme about seasons, and young children gain interest in the changes of their surroundings and feel and experience the beauty of flowers and plants.

The topic of flowers is interesting enough for young children in terms of season, and also for them to feel the aesthetic sense of nature. Playing with gardens or horticulture in houses helps raise children's humanity and sociality, and it provide a class of nature that helps them discover themselves; thus, children must have a close bond with nature for

Received (January 28, 2017), Review Result (March 18, 2017), Accepted (January 18, 2018) 
their sound development of body and soul [2]. Therefore, this study will provide the foundation to develop various teaching methods and curriculums through the process in which young children feel and enjoy the aesthetic sense and beauty of flowers as a natural object, and naturally learn about the role and circulation of plants in the ecosystem. In this process, this study will also determine the contents of education and meaning through the changes in the children.

\section{Research Methods}

\subsection{Research Subject}

The research subjects are Class B with 5-year-old children at A Kindergarten located in G City, and the research was conducted for four weeks in May 201.

\subsection{Data Collection}

Data was collected by taking pictures of the children in the flower project and recording their interactions. The recorded data was transcribed and analyzed, with the review by one fellow teacher, one professor and one expert.

\subsection{Research Procedure}

The development process of the project was carried out in the order of collecting thoughts, exploring, finale and reminiscing. When collecting thoughts, the child renting thoughts, the project was carry were determined through brainstorming of flowers based on their involvement in exploring through various activities. Based on the results, finale activities were selected and carried out, and the process of change in brainstorming and knowledge was examined through reminiscing.

\subsection{Data Analysis}

In order to examine the process of change in young children through the flower project, this study conducted qualitative analysis, data collection and expert analysis. Data was collected by filming video clips, taking pictures and making records of the researcher, which were reviewed by three experts in early childhood education and two professors. Qualitative case studies were analyzed by focusing on the process of activities rather than results or effects, and on discovering and understanding the meaning rather than measuring frequency or quantity.

\section{Beginning of the Project: Flowers are Pretty.}

\subsection{Plants are Precious}

The children were perceiving flowers as plants, and that these plants were to be valued and protected.

Teacher: If I say 'flower,' what else can you think of?

Mijeong: Mum... Plant... It's a plant.

Teacher: Yes, it's a plant. A flower is a plant.

Yujin: We must treasure the flower. Flowers are precious.

(Apr. 2, 2015. During brainstorming) 


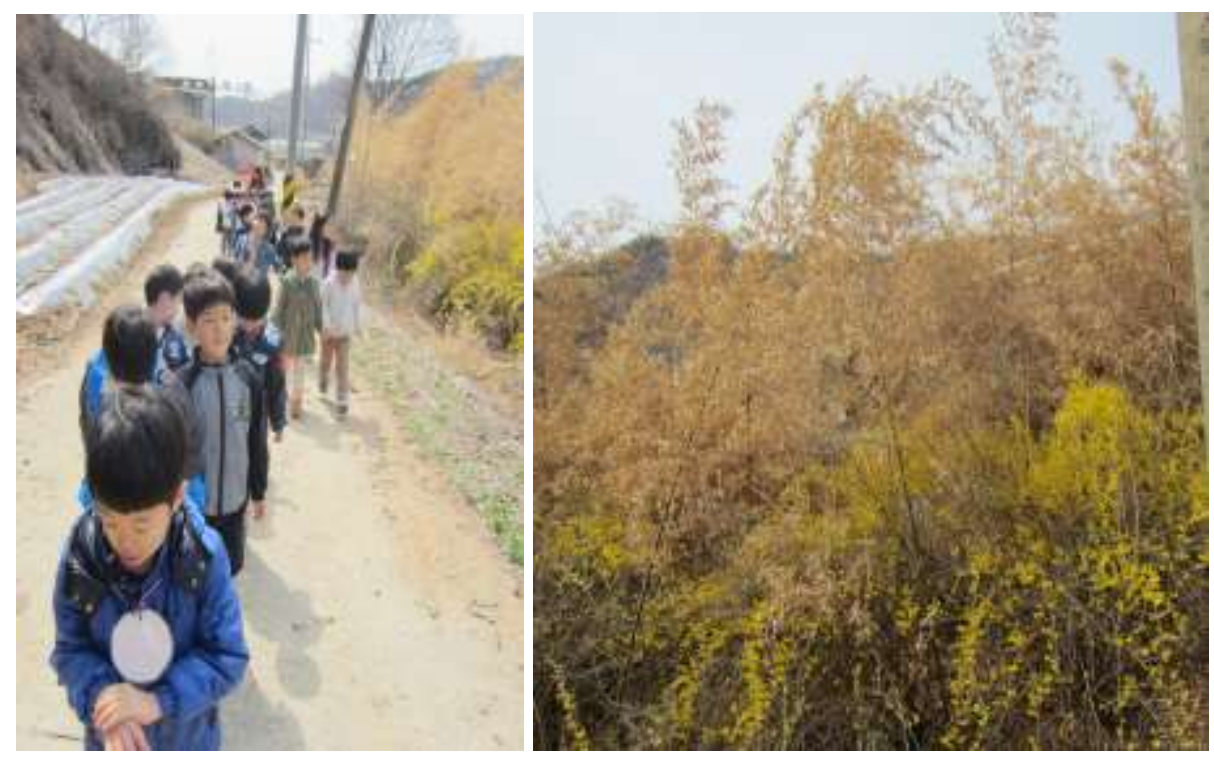

Figure 1. Meeting with Forsythia

This is well revealed in their brainstorming process, and especially in the process of classifying their thoughts and selecting subtitles
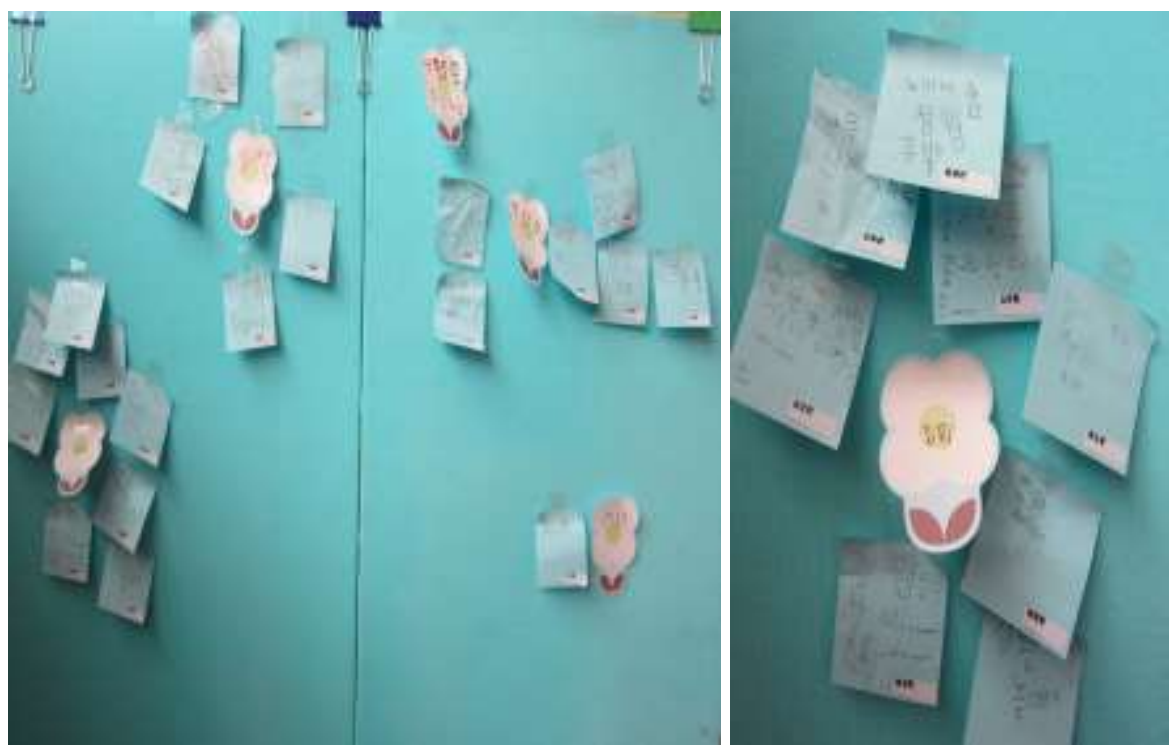

Figure 2. Brainstorming Process

\section{Exploring the Project Theme: Why are Flowers so Beautiful?}

\subsection{Let's go Meet Flowers}

After brainstorming, the children curiosity and interest in flowers grew bigger. They were taken to a garden of flowers for spring picnic then. The place displayed well-tended seedlings, flowers and potted plants. The children showed curiosity about the garden after watching the garden with well-tended flowers and the gardeners taking care of the flowers. 

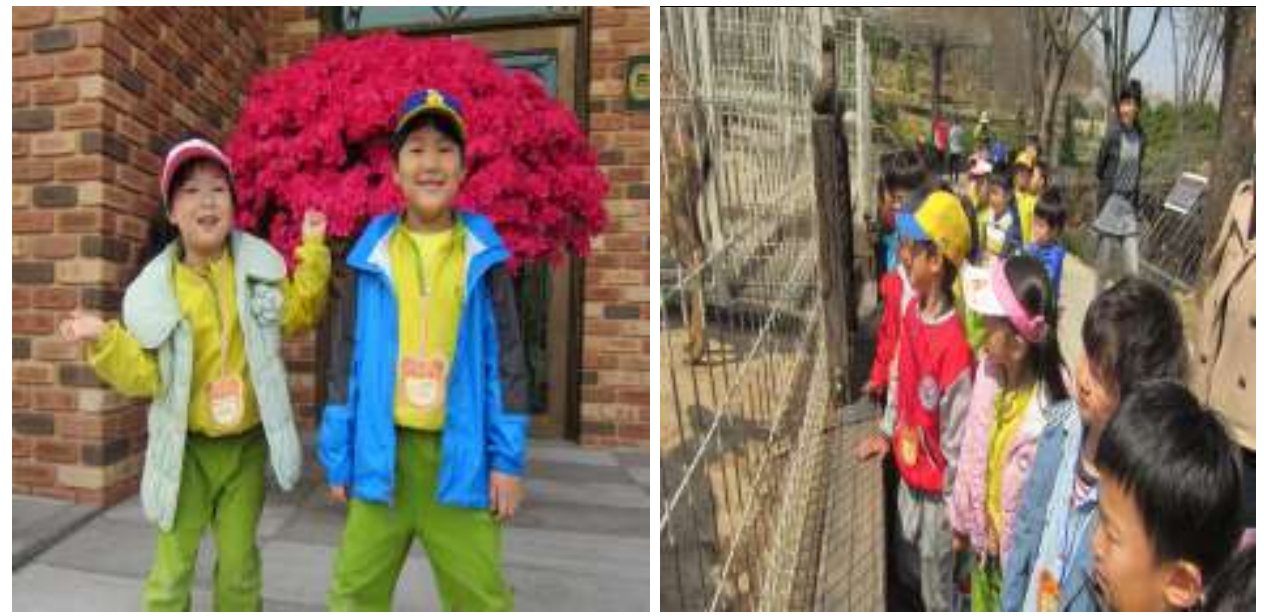

Figure 3. The Discovery of Flowers

They also showed interest in seedlings, which they newly found out about in their visit to the garden, and tried to learn more about various plants other than flowers with curiosity. They also showed interest in ways to beautifully grow and protect plants we can see around us just like the ones they saw in the garden, and talked about how to protect the plants.

Jeongmin: Teacher, teacher! The trees look just like Lego blocks.

Teacher: Oh yes, they really do! Our kindergarten also has really beautiful trees, right? Jeongmin: Yeah.

Yumi: The flowers are really pretty, too. They, too. so has ok?

Teacher: The flowers are really beautiful, so that can this hill and this place are decorated with the flowers. So people come here to relax and enjoy them.

(Apr. 17, 2015. During spring picnic)
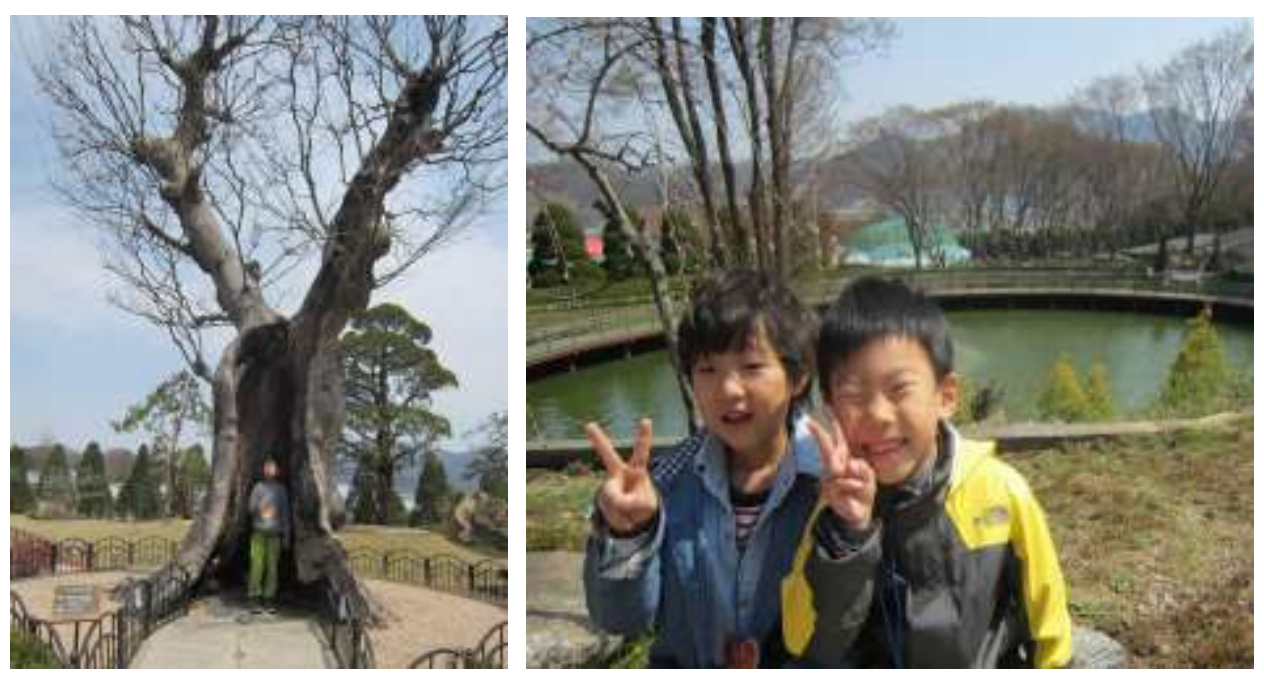

Figure 4. Be Curious About Plants

\subsection{It Feels Soft and Smells Good (Observation, Physical Expression)}

The children also participated in observing flowers, making physical expressions as flowers, and making flowers with various materials. In this process, they could explore flowers in multiple aspects, and encounter more abundant information and knowledge beyond the ones they already had in advance through the exploring activities. 


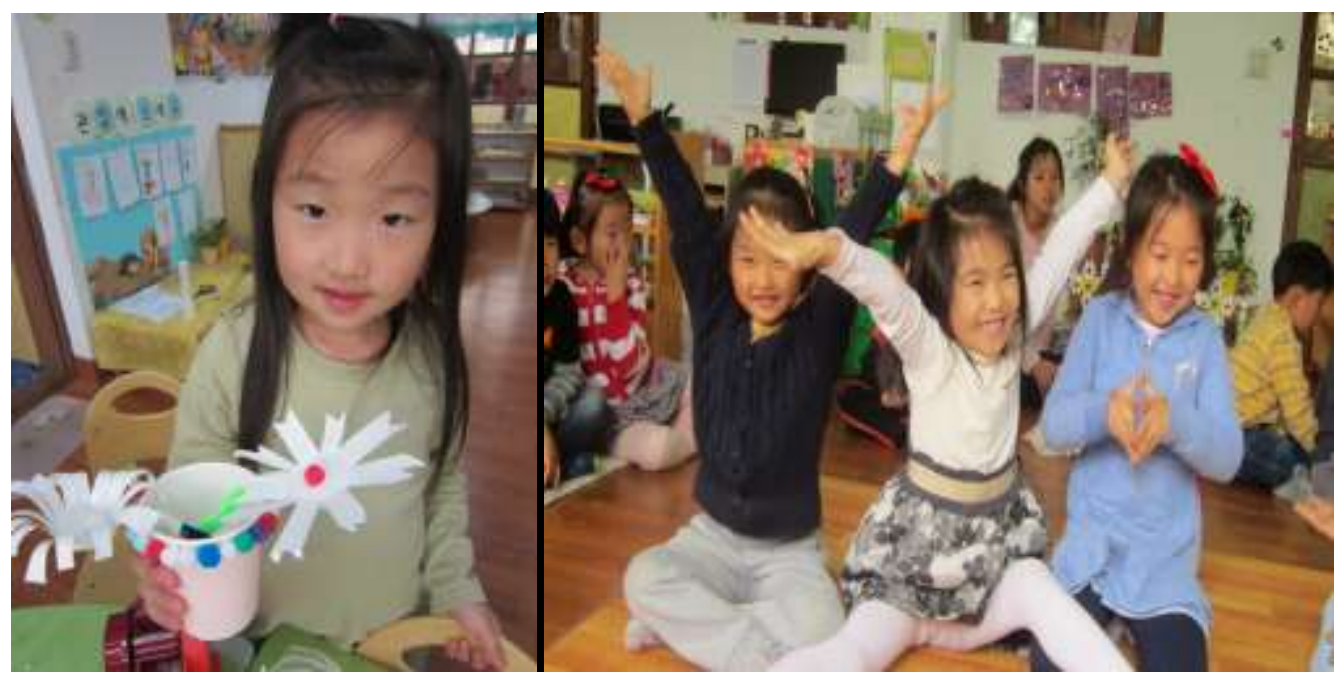

Figure 5. Flower Making and Flower Body Expression

They could expand their scope of information and knowledge about the plant structure or natural ecosystem through these activities
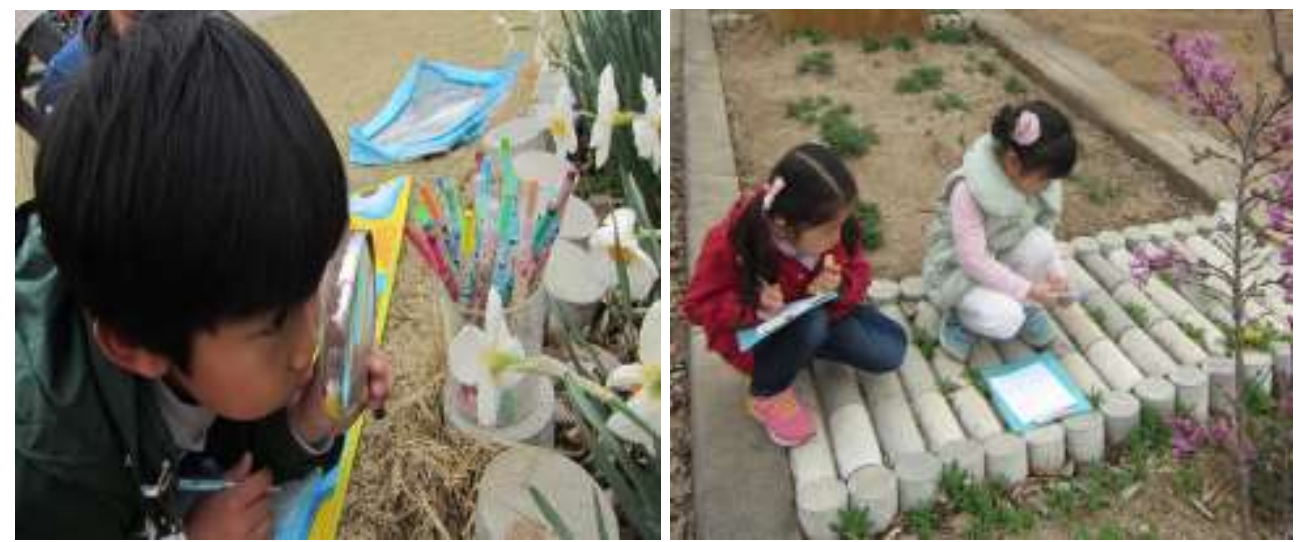

Figure 6. Observe the Delicate Details of the Flowers

Teacher: You just observed a flower. What was it like?

Yujin: It feels soft, and smells good.

(Apr. 20, 2015. During observation activity)
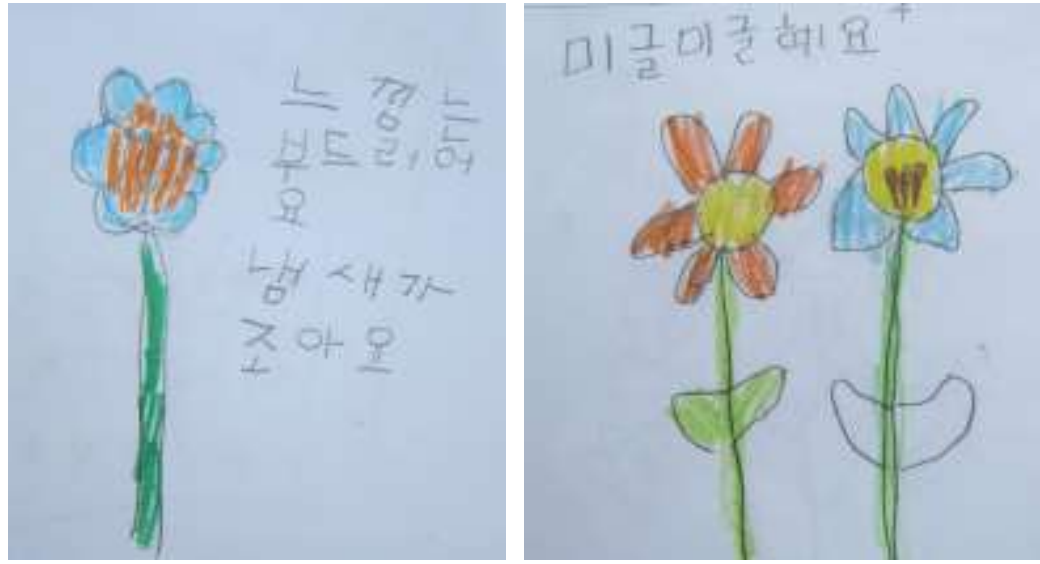

Figure 7. Children's Observation Record 


\section{End of the Project: The Garden of Flowers is Open}

\subsection{Make A Garden where there are Flowers At All Times}

The children came up with an idea to create a garden where there are beautiful flowers at all times. The teacher and the children thought about where to put the garden in the classroom, and designed it together. The children went through the process of creating a small garden in the classroom, filling it up with soil and planting flowers by reflecting their ideas.

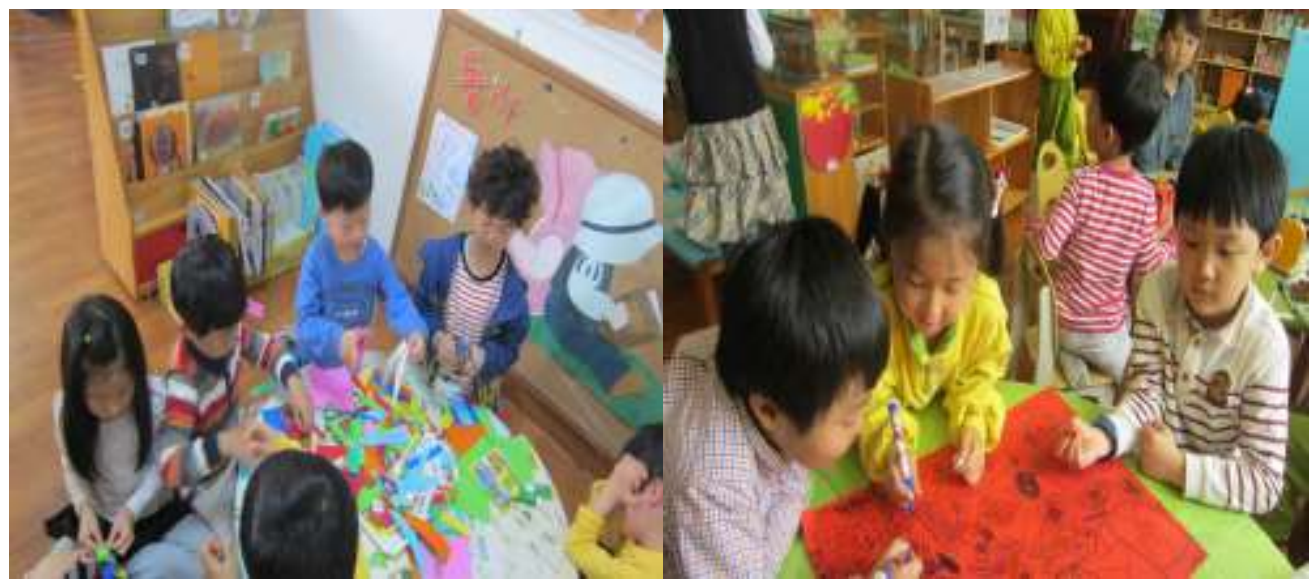

Figure 8. Making Flowers, Gardening Nameplate of Flowers

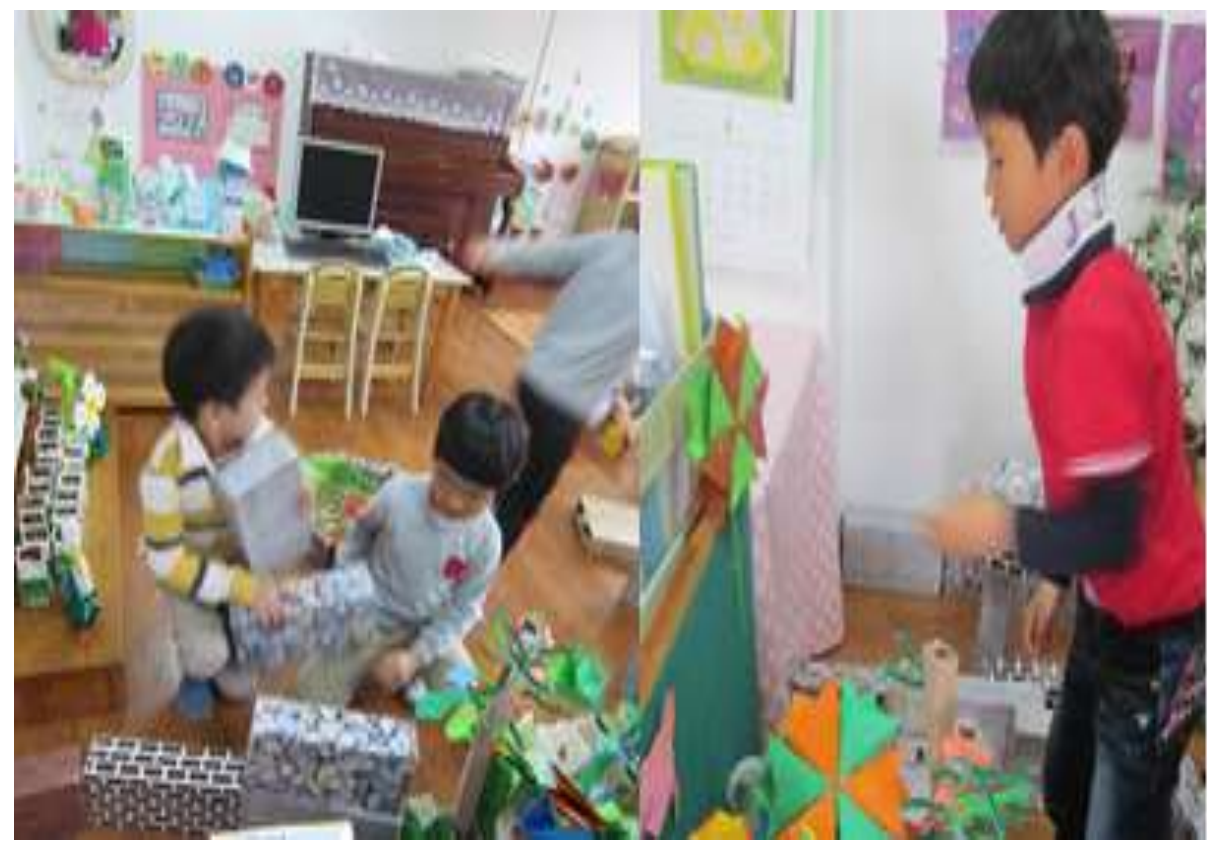

Figure 9. Flower Making Garden

When planting flowers, they found out about how to plant which flowers, and focused on creating an environment where such plants can grow well. 

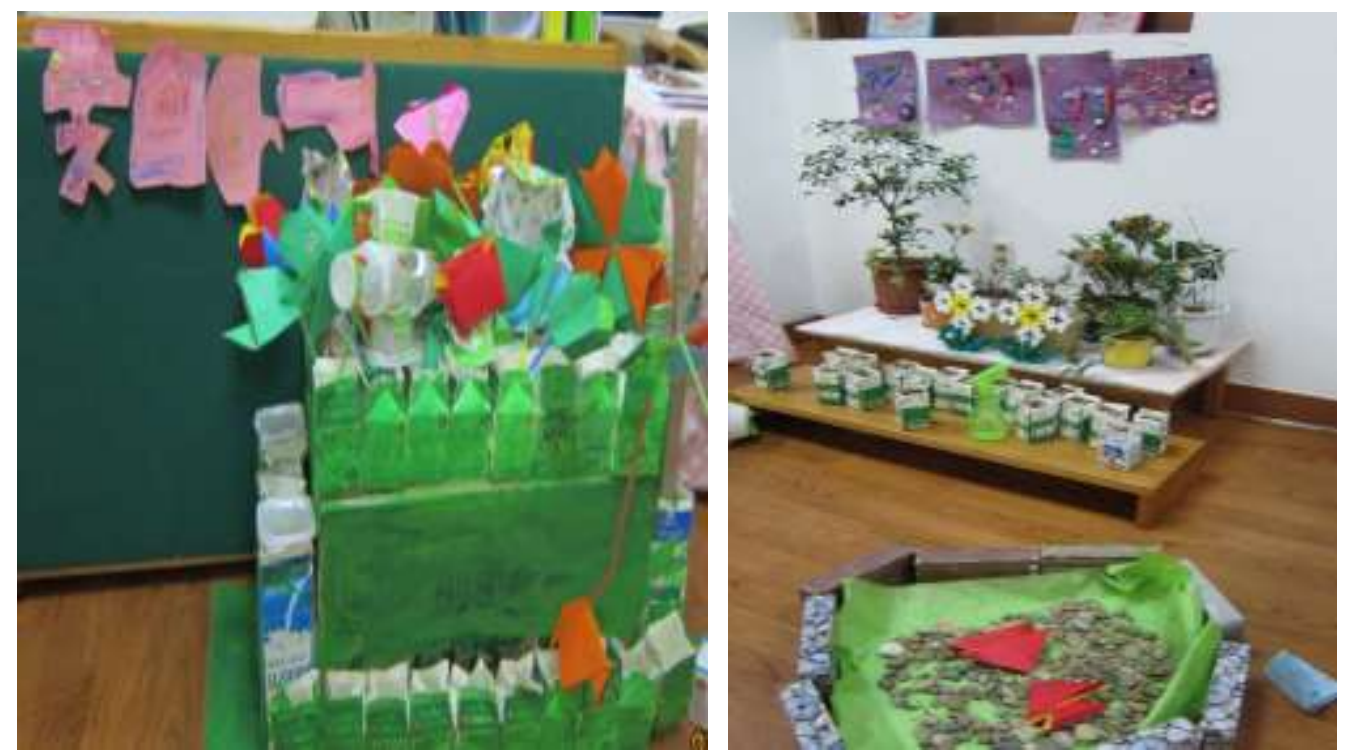

Figure 10. Completed Garden

\subsection{Come To The Garden of Flowers.}

While exploring the flowers, the children thought about the garden they saw during their picnic, and came up with the idea to make a garden with the flowers they recognized.

Thus, they participated in the activity of the garden of flowers by making a sign for the garden, invitations and flower books, and then inviting other children at the kindergarten.

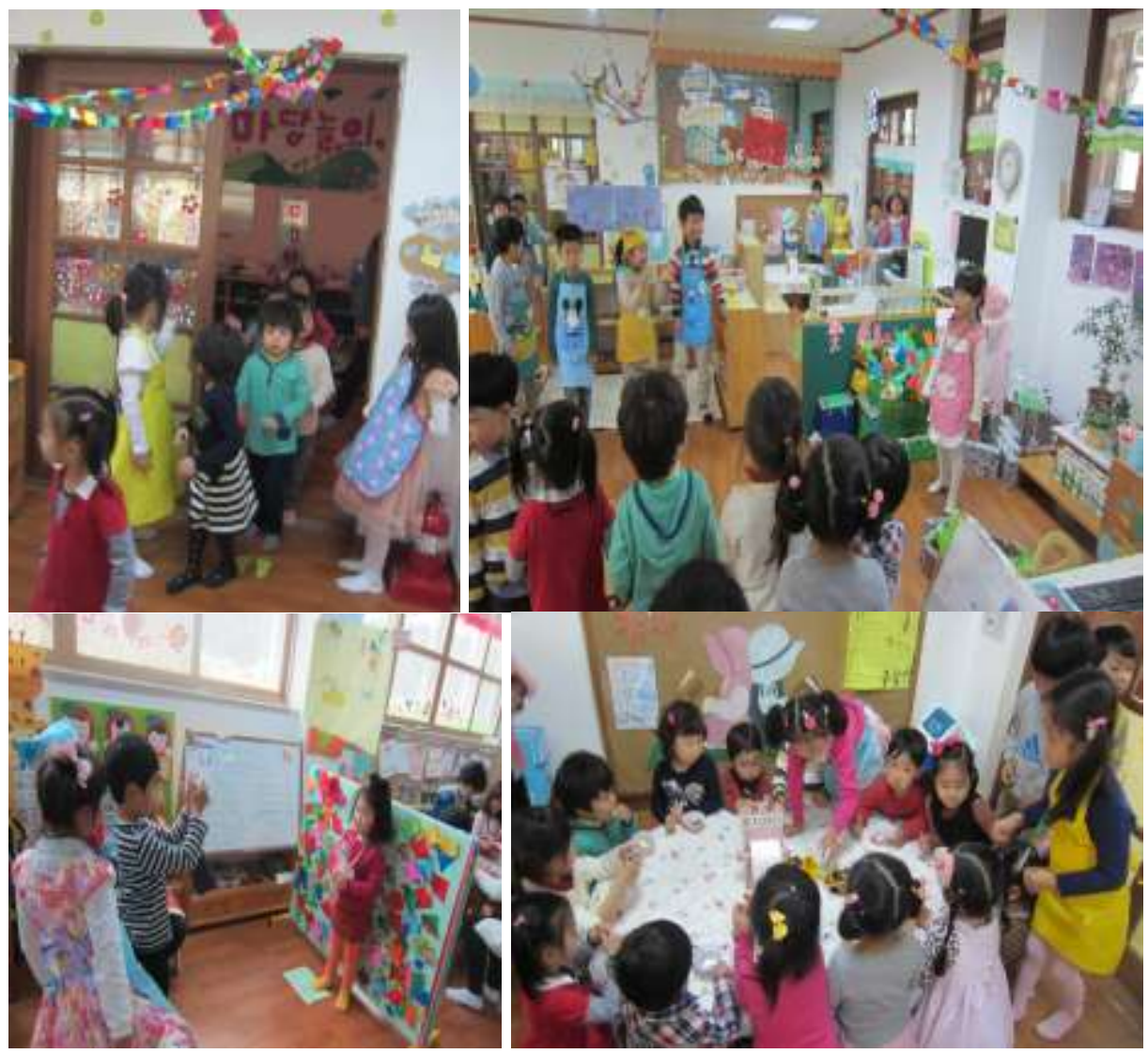

Figure 11. Flower Garden Festival Appearance 


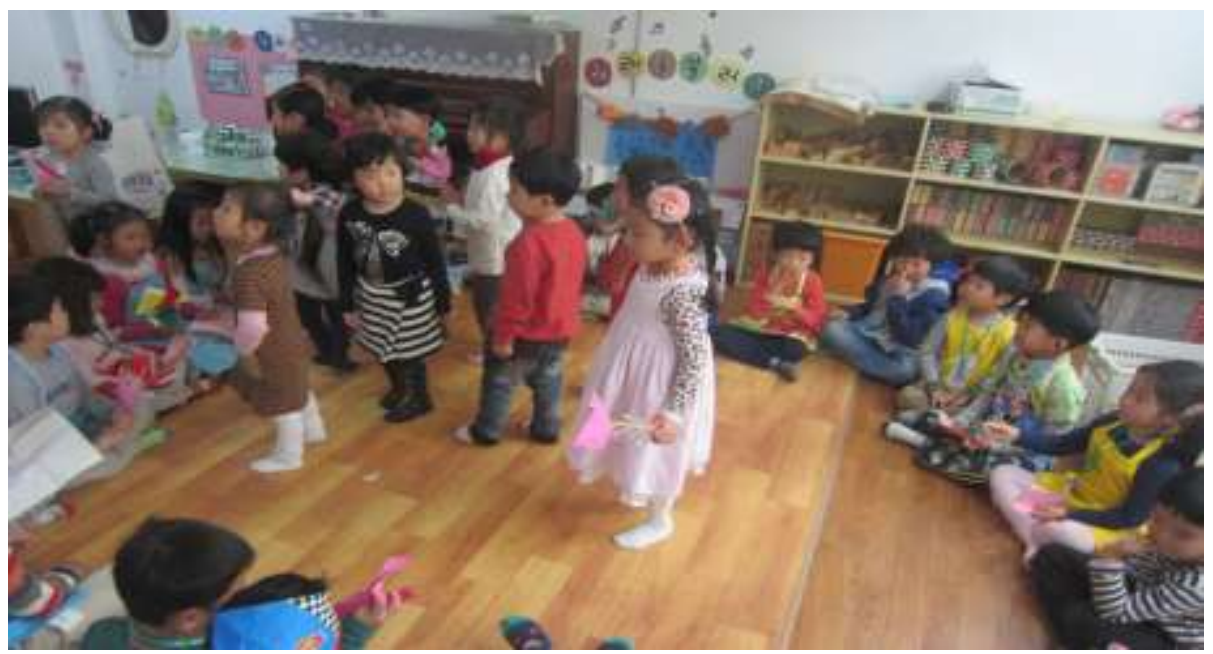

Figure 12. Thanks for Inviting

\section{Children that felt the Beauty of Flowers}

The children naturally expanded their interest in flowers into an interest in plants. They did not merely stop at thinking about flowers, but showed an interest in plants, which provided a momentum for them to have consciousness that plants must be protected and are precious. This showed that the project served as a medium for environmental education, and the children were engaged in intensive thinking about plants in the process. It has been found that the project activity promotes the development of infants and that accidents of infants can be expanded, and this is a result of many prior studies that were studied in the past, and the project activities were developed in various areas of infants You can know that it will help [3], [4], [5], [6], [7].

The children came to have interest in nature and ecosystem by exploring flowers. In terms of curriculum, there may be specific activities in the field of science education where natural phenomena are shared and explored[8]. The children grew interested in the structure and role of flowers in the process of exploring flowers, and showed a shift in their perceptions about nature in this process.

The children intensified and expanded their activities in association with their experiences related to flowers. It was found that they could think in association with their previous experiences through the project, and expand and carry out activities accordingly.

In many previous studies, many studies on the effectiveness of project activities were done, and it can be seen that project researches related to preliminary infant teachers were also conducted[9], [10]. Therefore, in addition to research on projects related to infants in the future, we will conduct more diverse research.

\section{Acknowledgments}

This paper is a revised and expanded version of a paper entitled [Make a Garden of Flowers] presented at [International Conferences AST 2017, Hanoi, Vietnam, February 9$12,2017]$.

\section{References}

[1] J. S. Lim, "Outdoor Space Survey and Learning Garden Plan of Kindergartens of the Bundang-gu Region of Gyeonggi-do", Dankook Universit, (2010).

[2] R. A. Wilson, "Environmental education programs for preschool children", J. Environ. Education, (1996), vol. 4, pp.28-33. 
[3] B. M. Kyoung and W. H. Jung, "The Influence of the a Project Approach on the Improvement of the Thinking Faculty of Preschoolers", Journal of Korean Child Care and Education, vol.8, no.5, (2012), pp.157-177.

[4] K. J. Young and K. H. Soon, "Effects of Preschoolers' Forest Activities based on Project Approach on Their Scientific Thinking Ability", The Journal of Education Research, vol.1, no.1, (2016), pp.55-75.

[5] S. S. Kyung and S. H. Ju, "The Effects of Mother and Father Project Activities on Young Children's Parent's Role Perspective and Empathic Ability", Korean Association of Human Ecology, vol.11, (2013), pp.302-304.

[6] Y. J. Hee, "Effects of Camera Project Language Activities on Verbal Skills and Creativity of Preschoolers", The Korea Contents Society, vol.14, no.12, (2014), pp.511-526.

[7] M. Y. Sim and L. H. Young, "The Effects of the Project Approach Method on Young Children's Measurement Ability and Mathematical Attitudes-"Wheel" Project Activity", The Korea Association of Child and Education, vol.54, no.9, (2008), pp.141-161.

[8] S. T. Hong, "Development of the horticultural activity program from ecological early childhood education perspective", Graduate School of Educaion Kyinggi University, (2004).

[9] Y. E. Ju, "A Study of Developing Key Contents for Self Directed Teacher Education Program with Project: Focused on Project-implementing", Korean Journal of Child Studies, vol.36, no.3, (2015), pp.195-213.

[10] L. O. Joo, "The Effects of the Cooperative Project Teaching-Learning Methode on Self-efficacy for Preservice Early Childhood Teachers", The Journal of Korean Teacher Education, vol.29, no.2, (2012), pp.321-343.

[11] K.-C. Kim and K.-E. Lee, "Make a Garden of Flowers", Proceedings of the International Conferences AST 2017, Hanoi, Vietnam, (2017).

\section{Authors}

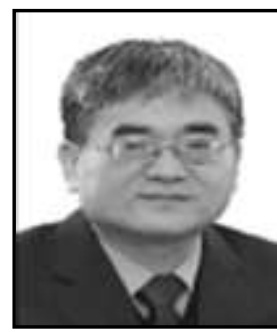

Kyung-Chul Kim, he is a Professor, Department of Early Childhood Education, Korea National University of Education.

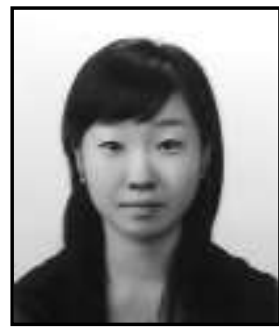

Ko-Eun Lee, she has a Doctor's course, Department of Early Childhood Education, Korea National University of Education. 
International Journal of Advanced Science and Technology

Vol.112 (2018) 